Reflections on Time and Politics 



\title{
Reflections on Time and Politics
}

\author{
Nathan Widder
}

The Pennsylvania State University Press

University Park, PennysIvania 


\section{Library of Congress Cataloging-in-Publication Data}

Widder, Nathan, I970-

Reflections on time and politics / Nathan Widder.

p.

$\mathrm{cm}$.

Summary: "Explores the nature of time and its implications for questions of politics, ethics, and the self. Shows how a conception of time that breaks with common sense notions of chronological order can help us rethink the understandings of identity, difference, power, resistance, and overcoming"-Provided by publisher.

Includes bibliographical references (p. ) and index.

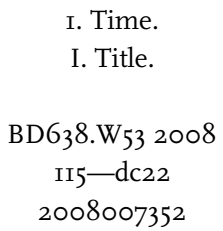

Copyright (C) 2008

The Pennsylvania State University

All rights reserved

Printed in the United States of America

Published by The Pennsylvania State University Press,

University Park, PA I6802-1003

The Pennsylvania State University Press is a member of the Association of American University Presses.

It is the policy of The Pennsylvania State University Press to use acid-free paper. Publications on uncoated stock satisfy the minimum requirements of American

National Standard for Information Sciences-

Permanence of Paper for Printed Library Material, ANSI Z39.48-I992. 
IN MEMORY OF MY FATHER, ROBERT WIDDER, (Oct. 23, I926-Feb. 2I, 2008), who faced everything that came his way with courage and dignity. 
In our failure to understand the use of a word we take it as the expression of a queer process. (As we think of time as a queer medium ...) -wittgenstein, Remarks on the Foundations of Mathematics, I.I27

We would know nothing of time and motion if we did not, in a coarse fashion, believe we see what is at "rest" beside what is in motion. - Nietzsche, The Will to Power, $\sqrt{520}$

Philosophy's sole aim is to become worthy of the event. -Deleuze And GUatTari, What Is Philosophy? p. I6o 